\title{
Prevalence of Cervical Intraepithelial Neoplasia (CIN) at Khulna Division of Bangladesh
}

\author{
AFROZA KHANAM ${ }^{1}$, ZANNATUL FERDOUS JESMIN ${ }^{2}$, FAUZIA BEGUM ${ }^{1}$, N AKHTER ${ }^{1}$, MST AKTER ${ }^{2}$, \\ SHAMSUN NAHAR ${ }^{3}$, AR BARUA $^{4}$, A NESSA ${ }^{5}$
}

\begin{abstract}
Summary:
Back ground: Cervical cancer is the most common genital tract cancer and the important cause of cancer death among Bangladeshi women. Information about actual number of women living with preinvasive phase of cervical cancer and their diagnosis and treatment is limited. For strengthening the programme and policy for cervical cancer prevention, the baseline prevalence of cervical intraepithelial neoplasia ( CIN) need to be assessed.
\end{abstract}

Methods: This population based study aimed to determine the prevalence of CIN among women of Khulna division of Bangladesh. Data has been collected from four upazila of four districts of Khulna division. VIA and colposcopy and histopathology was used for detection of cervical pre-cancers and early cancers among 1232 women of the mentioned population.

Results: Crude prevalence of CIN was $5.84 \%, C I N-I I 1.1 \%$ and $C I N-I I I .73 \%$ in colposcopically directed biopsy. Ninety two participants with CIN received treatment at the Colposcopy Clinic of Obstetrics and Gynaecology department of Khulna Medical College Hospital ( $\mathrm{KMCH})$.

Conclusion: This population based prevalence study of CIN and socio demography would have conducive effect on future cervical cancer prevention programme.

Key word: CIN, population prevalence, Bangladesh.

\section{Introduction:}

Cervical cancer is the fourth most common cancer in women with an estimated 527,624 new cases and 265,653 deaths in 2012 . Around $85 \%$ of these new cases and $86 \%$ of deaths occur in less developed countries. In Bangladesh, cervical cancer is the $2^{\text {nd }}$ most common cancer in women, with agestandardized rates (ASRs) for incidence and mortality much higher than the global average statistics (Incidence rates: 19.3 vs. $14.0 / 100,000$ women; Mortality rates: 11.5 vs. $6.8 / 100,000$ women). ${ }^{1}$ Death from cervical cancer is preventable by early detection in precancerous stage by screening for $\mathrm{CIN}$ (cervical intraepithelial neoplasia). Between 1988-1994 cytological screening by national call and recall system reached $85 \%$ coverage of target population and had reduced the incidence and mortality from cervical cancer in England. ${ }^{2}$ Coverage of cervical cancer screening in developing countries is low, $19 \%$ on average, compared to $63 \%$ in developed countries, and reported as low as $1 \%$ in Bangladesh . Older and poor women, who are at the highest risk of developing cervical cancer, are least likely to be screened. Challenges in introducing Cytological screening in low and middle -income countries led to alternative screening strategies that must be adapted to meet the specific needs of individual countries. ${ }^{3,4}$ In Bangladesh visual inspection of cervix with acetic acid ( VIA) is an accepted method of cervical cancer screening at maternal and child

1. Associate Professor, Obst and Gynae, Khulna Medical College.

2. Assistant Professor, Obst and Gynae, Khulna Medical College.

3. Professor, Obst and Gynae, Khulna Medical College.

4. Professor, Pathology, Bangabandhu Sheikh Mujib Medical University( BSMMU)

5. Professor Obst and Gynae, Bangabandhu Sheikh Mujib Medical University (BSMMU).

Address of Correspondence: Dr. Afroza Khanam, Associate Professor, Obs and Gynae, Khulna Medical College. Email: ak_dr@yahoo.com, Mobile: 01711830989 
welfare centers (MCWC), district hospitals (DH), medical college hospitals $(\mathrm{MCH})$ and Bangabandhu Sheikh Mujib Medical University (BSMMU). VIA is administered by trained family welfare visitors (FWV), senior staff nurses (SSN) and doctors. Screenpositive women are referred to BSMMU and Medical college Hospitals for colposcopic evaluation and management. ${ }^{5}$ Present study was conducted using this infrastructure. Quality assurance body report of cervical cancer screening program in 44 districts of Bangladesh (2004, published in 2008) suggested that coverage of target population was low and screening was opportunistic, the compliance to colposcopy was good. ${ }^{6}$ So prevention of cervical cancer needs wide coverage of target population with budgetary allocation and development of manpower. Population Prevalence of cervical intraepithelial neoplasia(CIN) is an important indicator and help to judge the potential cervical cancer burden in the community . Regular screening by VIA and treating precancerous lesion, even by single visit screen and treat approach is recommended in resource poor settings to prevent cervical cancer. ${ }^{7,8}$ In rural Andhra Pradesh, South India, a total of 18,869 women screened by a single round of VIA, the prevalence of cervical intraepithelial neoplasia (CIN) 2+ lesion rate was $1.05 \%$, with a VIA positive rate of $10.75 \% .{ }^{9}$ In China high risk HPV(HRHPV) positive was $31.4 \%$, age standardized prevalence of CIN II $1.5 \%$ and $0.7 \%, \mid$ CIN $31.2 \%$ and $0.6 \%$ respectively in rural and urban location . CIN 3 steadily increased with age peaking in $45-49$ years women due to lack of lesion removal through screening ${ }^{10}$. In Bangladesh cervical cancer causes death of women when they are raising the family and cases are diagnosed late as they missed the opportunity for cure by screening. For preventive program and designing interventions at national level, it is important to know the baseline prevalence of CIN , but such data is not available. Study on prevalence of $\mathrm{CIN}$ in this research was performed to detect the prevalence of CIN in an unscreened population of Khulna division of Bangladesh. Documentation of sociodemography and reproductive history, management relevant to women at risk of cervical cancer was also done. The findings of this study may help implementing population based organized screening services for cervical cancer with expectation of reducing cervical cancer prevalence in Bangladesh.

\section{Methodology:}

This cross-sectional and population based study was carried out in four randomly selected sub districts(upazillas ) with cervical cancer screening facilities provided for four districts of Khulna division, by the Department of Obstetrics and Gynaecology of Khulna Medical College Hospital $(\mathrm{KMCH})$ and BSMMU from March 2014 to June 2014. The minimum sample size from one upazila was around 220 following the standard sample size estimation formula with $3 \%$ prevalence of CIN with $95 \%$ confidence interval. As randomly selected four sub districts were considered in this study, the sample size was about $880(220 \times 4)$ or more. Resource persons (colposcopists) from $\mathrm{KMCH}$ and BSMMU provided daylong orientation to Nurses and Field Staffs of the selected Upazilla health complexes on methodology of the study, counselling, motivation, recruitment of women, and referral system. Married women age between 25-55 years able to understand written and/or oral information, mentally able to provide informed consent were recruited through door to door visits by health workers. Women with chronic illness, women with pregnancy and women already screened were not included in the study. Data collected from selected women of four upazilas after initial recruitment of field staffs on specified dates. Almost equal number of participants were selected from each ward of the selected upazillas. Participants from alternate household were requested to attend UHCs on a selected date. If participants from particular household disagreed to participate, participants were recruited from the next household. After initial recruitment 350 participants were given appointments to have clinical examination, VIA and colposcopy at respective Upazilla Health complex. About 35-40 women were invited each day for examinations. A pretested questionnaire was used as data collection instrument by face to face interview (by Research Assistant/ Doctor /Nurse). Interview was conducted under supervision of investigators. At the UHCs, the women were further counselled regarding examination procedure under privacy. A temporary arrangement for colposcopy were 
developed at selected UHCs. All enrolled women underwent VIA and colposcopy. Abnormal colposcopy findings were further evaluated by punch biopsy and endocervical evaluation if needed. After the procedure women had further counselling about possible test results, need for follow up, necessity of biopsy, referral for treatment. All histopathological examinations were done at the Department of Pathology of BSMMU. CIN cases were called at colposcopy clinic of $\mathrm{KMCH}$ for necessary managements. Ethical clearance were taken from the Institutional Review Board (IRB) of BSMM. Interview questionnaire collected information about socio-demographic and reproductive health characteristics, examination results. Completed data were reviewed, edited and processed for computer data entry. The data analysis was performed using Statistical Package for the Social Sciences (SPSS) Version 17.0. The prevalence of CIN was calculated with $95 \%$ confidence interval.

\section{Results:}

In Khulna division, 1232 women of between 25-55 years age groups participated in the study. Participants from different villages of four upazillas of four distrcts (Jessore, Khulna, Bagerhat, and Sathkhira Fig 1) were almost equal number about (260-300 women) (Table 1). Socio- demographic data of study population showed majority were between $30-49$ years age group (71\%). A good number had primary education (44.2\%). Majority were housewives (96.3\%). More than half of women $(61.8 \%)$ married before 18 years of age and $1142(92.7 \%)$ had their first delivery between 14-25 years. Mean Age at marriage $16.76 \pm 3.81$ years and mean age at first delivery $19.26 \pm 4.475$ years. Mean Parity was 233 . Ninety seven percent were married one time and majority were living with husband (93.5\%). Around $9 \%$ of their husband had more than one wives. About two third of the families belonged to low and middle class income groups (monthly income less than Tk 10,000). Seventy five percent of women were Muslim and rest were Hindu (Table 2).

Prevalence of CIN was $5.84 \%$. In colposcopically directed biopsy, CINI 4.0\%, CIN-II 1.1\% and CINIII. 73\% (Table 3). Colposcopy and histopathology correlation in diagnostic accuracy documented and
Sensitivity and Specificity of colposcopy were $60.9 \%$ and $98.65 \%$ respectively (Table 4 ). Prevalence by age showed that CIN II and CIN III were more in 25-44 age group (Table 5). $90 \%$ of CIN belongs to low socioeconomic group (Table 6). Treatment received were periodic screening after 5 year 1188(96.9\%), LEEP 18(1.8\%), Cold coagulation $25(2.1 \%)$, and admission in Oncology department 1(.1\%)(Table 7 )

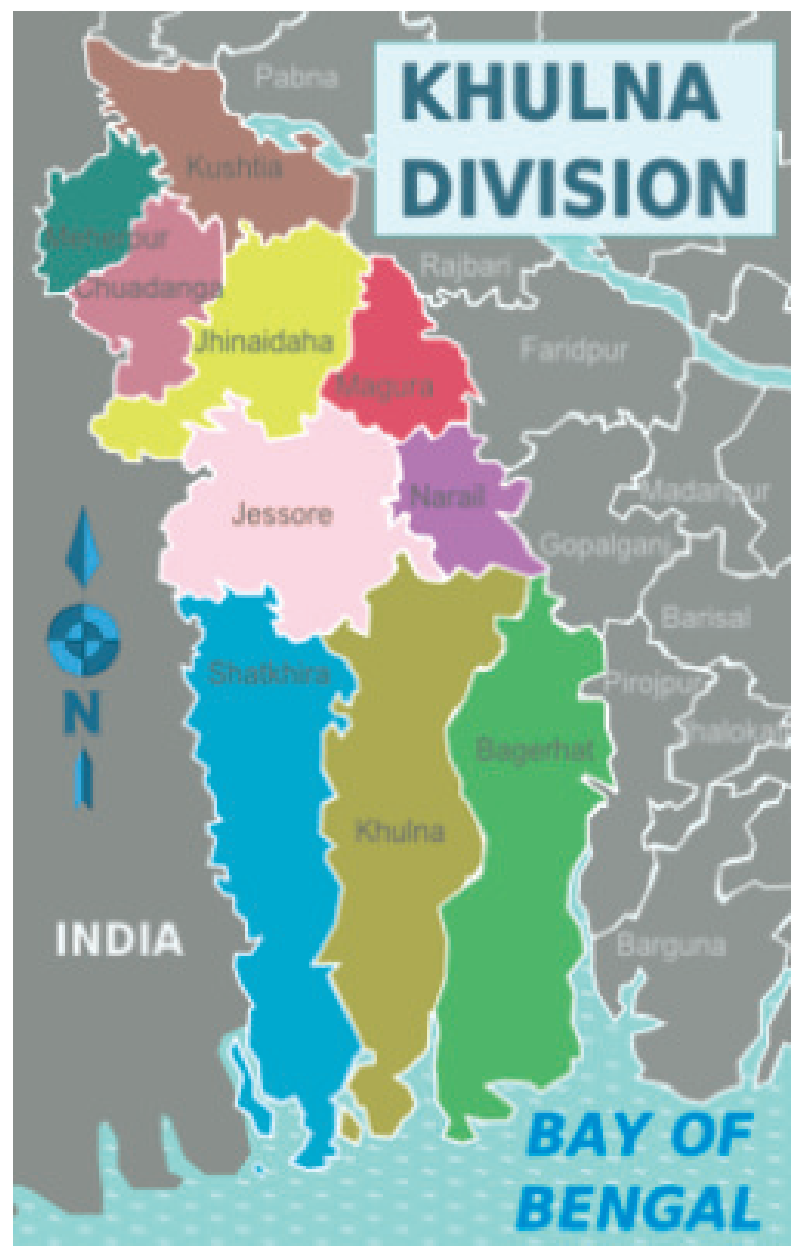

Fig.-1: Districts of Khulna Division.

Table-I

Geographical distribution of Study population

\begin{tabular}{lccc}
\hline District & Upazilla & Frequency & Percent \\
\hline Jessore & Avaynagar & 327 & 26.5 \\
Khulna & Fultola & 267 & 21.7 \\
Bagerhat & Mongla & 319 & 25.9 \\
Sathkhira & Tala & 319 & 25.9 \\
\hline Total & 1232 & 100.0 & \\
\hline
\end{tabular}


Table-II

Socio-Demographic and Reproductive

Characteristics of Women $(n=1232)$

\begin{tabular}{l}
\hline Characteristics \\
\hline Age Group \\
25-29 years \\
30-34 years \\
35-39 years \\
40-44 years \\
45-49 years \\
50-55 years \\
Religion \\
Islam \\
Hindu \\
Education of women \\
Illiterate \\
Primary \\
Secondary \\
Higher Secondary \\
Graduate \& above \\
Occupation of women \\
House Wife \\
Labour \\
Service \\
Business \\
Teacher
\end{tabular}

Occupation of Husband

$\begin{array}{lc}\text { Unemployed } & 11(0.9) \\ \text { Labour } & 195(15.8) \\ \text { Farmer } & 451(36.6) \\ \text { Business } & 327(26.5) \\ \text { Driver } & 19(1.5) \\ \text { Service holder } & 194(15.7) \\ \text { Teacher } & 18(1.5) \\ \text { Not alive } & 17(1.4)\end{array}$

Age at marriage

17 years and below

$761(61.8 \%)$

18-25 years

26-35 years

$439(35.6 \%)$

$25(2 \%)$

36 and above

$224(18.2)$

$270(21.9)$

$283(23.0)$

$193(15.7)$

135(11.0)

$127(10.4)$

$933(75.7)$

$299(24.3)$

$184(14.9)$

$545(44.2)$

368(29.9)

85(6.9)

$50(4.1)$

$1187(96.3)$

$3(.2)$

28(2.3)

$7(.6)$

$7(.6)$
Table-III

Histopathology Finding in colposcopy guided biopsy

\begin{tabular}{lcc}
\hline Histopathology & Frequency & Percent \\
\hline Normal & 21 & 1.7 \\
CIN-I & 49 & 4.0 \\
CIN-II & 13 & 1.1 \\
CIN-III & 9 & 0.7 \\
Squamous Cell Carcinoma & 1 & 0.1 \\
\hline Total & 1232 & 100.0 \\
\hline
\end{tabular}

Table-IV

Colposcopy - Histopathology Co relation

\begin{tabular}{lcccccc}
\hline Colposcopy & \multicolumn{5}{c}{ Histopathology } \\
\cline { 2 - 7 } & Normal & CIN-I & CIN-II & CIN-III & $\begin{array}{c}\text { Sq. } \\
\text { cell Ca }\end{array}$ & No \\
\hline Normal & 0 & 0 & 0 & 0 & 0 & 1139 \\
CIN-I & 17 & 36 & 7 & 2 & 0 & 62 \\
CIN-II & 3 & 12 & 2 & 2 & 0 & 19 \\
CIN-III & 1 & 1 & 4 & 5 & 0 & 11 \\
Squamous & 0 & 0 & 0 & 0 & 1 & 1 \\
Cell Ca & & & & & 1 & 1232 \\
\hline Total & 21 & 49 & 13 & 9 & 1 \\
\hline
\end{tabular}

Table-V

Types of CIN in different age groups

\begin{tabular}{lccccc}
\hline \multirow{2}{*}{ Age group } & \multicolumn{5}{c}{ Histopathology Finding } \\
\cline { 2 - 6 } & Normal & CIN-I & CIN-II & CIN-III & $\begin{array}{c}\text { Sq. Cell } \\
\text { Ca. }\end{array}$ \\
\hline 25-29 Years & 6 & 15 & 3 & 2 & 0 \\
30-34 Years & 3 & 12 & 6 & 1 & 0 \\
35-39 Years & 5 & 12 & 3 & 5 & 1 \\
40-44 Years & 5 & 7 & 0 & 1 & 0 \\
45-49 Years & 1 & 2 & 0 & 0 & 0 \\
50-55 Years & 1 & 1 & 1 & 0 & 0 \\
\hline Total & 21 & 49 & 13 & 9 & 1 \\
\hline
\end{tabular}


Table-VI

Socioeconomic Status and CIN

\begin{tabular}{|c|c|c|c|c|c|c|c|}
\hline \multirow{2}{*}{$\begin{array}{l}\text { Monthly Family } \\
\text { Income }\end{array}$} & \multicolumn{6}{|c|}{ Histopathology Finding } & \multirow[t]{2}{*}{ Total } \\
\hline & Normal & CIN-I & CIN-II & CIN-III & & Not Necessary & \\
\hline Taka 3000 or less & 4 & 5 & 0 & 2 & 0 & 121 & 132 \\
\hline Taka 3001-6000 & 6 & 19 & 5 & 3 & 0 & 411 & 444 \\
\hline Taka 6001-10000 & 8 & 18 & 5 & 3 & 1 & 319 & 354 \\
\hline Taka $>10000$ & 3 & 7 & 3 & 1 & 0 & 288 & 302 \\
\hline$\overline{\text { Total }}$ & 21 & 49 & 13 & 9 & 1 & 1139 & 1232 \\
\hline
\end{tabular}

Table-VII

Advice and Treatment of participants

\begin{tabular}{lcc}
\hline Valid & Frequency & Percent \\
\hline Follow-up after 3 years & 1188 & 96.9 \\
LEEP Biopsy & 18 & 1.8 \\
Cold Coagulation & 25 & 2.1 \\
Admission in Oncology & 1 & 0.1 \\
\hline Total & 1232 & 100.0 \\
\hline
\end{tabular}

\section{Discussion:}

Data on the prevalence on cervical intraepithelial neoplasia in this country is not known. It is very time needed to initiate community screening and educational awareness for screening for prevention and control of cervical cancer. CIN is a premalignant lesion that may exist at any one of three stages $\mathrm{CIN}$ $1, \mathrm{CIN} 2$ and CIN3. If left untreated CIN 2 and CIN 3 (collectively referred to as $\mathrm{CIN} 2+$ )can progress to cervical cancer. It is estimated that approximately 1 $2 \%$ of women have CIN2+ lesion each year . ${ }^{11}$ IARC estimated about one third of global cervical cancer burden in south east Asia and every year 11,956 new cases of cervical cancer are detected in Bangladesh and 6582women die of the disease. There are multiple modalities of cervical cancer prevention covering the targeted population. Epidemiological study suggested a causal relation with sexual activity and Human papilloma viruses.High risk types of HPV (Mostly 16and18)found in 50-80\% of CIN2 and CIN 3 lesions and $90 \%$ of cervical cancer. ${ }^{12}$ HPV geno type distribution showed considerable variation globally ${ }^{13}$ However PCR based HPV typing is not feasible in mass screening ${ }^{14}$. Many researches have focused on HPV types, scope of prophylactic and therapeutic vaccines, improve effectiveness of screening that was found in ATHENA trail, even then periodic screening needs to be continued. ${ }^{15,16}$

Our knowledge in pathogenesis of cervical cancer opened a window of cure. ${ }^{17} \mathrm{CIN}$ are evident on cytology, histology, and aided visual examination. Screening on high-risk women once or twice in their lifetime using a highly sensitive test, with an emphasis on high coverage (>80\%) of the targeted population for developing countries will have to find adequate financial resources, infrastructure and elaborate surveillance mechanisms for screening ${ }^{18}$. There is also suggestion that cancer screening should be a component of public health programme in developing country. ${ }^{19}$ Population prevalence of $\mathrm{CIN}$ is an important indicator to judge the disease burden in the community. Information about prevalence of CIN in Bangladesh was not available. Among 1232 women in 25-55 age group,we reported normal colposcopy $1139 / 92.5 \%$ and biopsy proven CIN I 49/4\%, CIN II 13/1.1\%, CIN III 9/.73\%. A study in Egypt prevalence found $3.3,0.84$ and $0.27 \%$ for CIN I, CIN II and CIN III, respectively by VIA. Prevalence of CIN II or higher was $1.11 \% .20$

Our study revealed CIN 1 was more prevalent in young age group 25-30 year and CIN 2 and CIN3 more common in older age group of 35- 39 years though statistically were not significant .Factors affecting prevalence of HPV infection and CIN are many. Age trends of high grade lesion peak at 25-40 years in Europe, Middle East, Africa and Asia and at relatively younger age in North America ( $<30$ years). We documented between 25-44 years. Variation in age pattern likely to attributable to difference in age at screening, frequency, coverage and rate of follow up, histological evaluation, processing, referral rate and diagnostic interpretation and HPV typing co testing and status of vaccinaton. ${ }^{21} \mathrm{~A}$ pooled analysis 
of data from India documented crude prevalence of $\mathrm{CIN}-1, \mathrm{CIN}-2$, CIN-3 reported were $2.9 \%, .6 \%$, and $.4 \%$ and that of invasive cancer $.2 \%$ among women between 30-65 years. CIN3 peaks at 35- 39 years and mean age $40.0 \pm 8.4$ years and decline in sixth decade, were found comparable to our study. In our study CIN 3 could not detected in 55 years group. ${ }^{22}$ In this study population sexual life started at younger age after marriage and mean age of marriage 16.76 \pm 3.81 years, low literacy, high parity and low income population and land less family were other contributory cofactors. ${ }^{23}$ Prevalence of CIN in HIVinfected women found to be two to five times more than HIV-uninfected women. ${ }^{24}$ Our study did not include any known case of HIV positive woman. All CIN were detected by Colposcopy and histopathology. Study group provide follow up and local treatment of biopsy proven CIN including CIN1 for protocol and ethical reason,though there is a low risk of of progression of CIN 1 or less $(1.6 \%) .{ }^{25}$ Even younger women with low grade cytological lesion and with a single HPV test may not be useful in determining which one worthy - follow up or treatment. In our population HPV status is unknown. ${ }^{26}$ Most of the time cases of CIN can be treated which are effective for more than $90 \%$ of cases, with $10 \%$ chances of recurrence 27 . Treatments available are cryotherapy, large loop excision of the transformation zone (LLETZ, or LEEP), and cold knife conization (CKC). ${ }^{28}$ Management of participants were advice for periodic screening, LEEP procedure, ablation by thermo coagulator. Outpatient therapy, employing such methods combined with proper follow-up, is appropriate for dealing with visible lesions on the ectocervix. Depending on the method used and the severity of lesion cure rates range from $80 \%$ to $95 \%$, with free margin and adequate depth in histopathology. ${ }^{29}$ Follow up following CIN treatment needs to be focus and found less than $50 \%$ in colposcopy clinic of Bangladesh, which is not satisfactory without HPV typing co testing ${ }^{30}$. We diagnosed one case with invasive lesion. The clinical staging of cervical cancer is the single most important prognostic factor and should be carefully evaluated in choosing optimal treatment between surgery and radiotherapy, with or without chemotherapy. ${ }^{31}$ Strength of this study were many, sample was population based covering different villages, large sample size with proper design, similar demography, rural habitat, homogenus ethnic group, repeated scrutiny by team throughout study period, diagnosis by colposcopy and histology. This research conducted by master trainer colposcopist from university and medical college. ${ }^{32,} 33$ Other observation was this study has created interest and awareness for cervical screening in community ${ }^{34}$. This might have conducive effect of future VIA ,HPV based screening and vaccination. Limitation of study we did punch biopsy and blinded review of histological report were not done in cases of diagnostic disparity with colposcopy. Other challenges were women's shyness and low awareness about risks and screening for cervical cancer and age group data of population. Health education on cervical cancerfor both man and women would made such type of study more fruitful. ${ }^{35}$

\section{Conclusion:}

Prevalence of cervical intraepithelial neoplasia was $5.8 \%$ and CIN2+ lesion were common in 25-44 aged multipara women with low income. There was almost no information on baseline prevalence of cervical precancer in Bangladesh. Population prevalence study of CIN in Khulna Division of Bangladesh would not only helps in planning appropriate national screening strategies but also provides key inputs for resource allocation for this global health problem with priority. Results obtained from this study would helpful for implementation of cervical cancer prevention strategy in Bangladesh and provide useful information to other developing countries.

\section{References:}

1. Ferlay J, Soerjomataram I, Ervik M, Dikshit R, Eser S, Mathers C, Rebelo M, Parkin DM, Forman D, Bray, F. GLOBOCAN 2012 v1.0, Cancer Incidence and Mortality Worldwide: IARC CancerBase No. 11 [Internet]. Lyon, France:International Agency for Research on Cancer; 2013. Available from: http:// globocan.iarc.fr, accessed on 18/12/2013.

2. Quinn M, Babb P, nifer Jones, Elizabeth Allen Effect of screening on incidence of and mortality from cancer of cervix in England: evaluation based on routinely collected statistics BMJ 1999; 318:904.

3. Emmanuela Gakidou Stella Nordhagen,Ziad ObermeyerZ Coverage of Cervical Cancer Screening in 57 Countries: Low Average Levels and Large Inequalities. PLOS:one June 2008;5(6):0863-0867. 
4. Sankaranaranan R. Screening for cancer in low and middle income countries. Annals of Global Health 2014; 80 (5) 412- 417.

5. Ahmed T, Ashrafunnessa, Rahman J Development of a Visual Inspection Programme for Cervical Cancer Prevention in Bangladesh. Elsevier Reproductive Health Matters 2008; 16 : 78-85.

6. Basu P, Ashrafunnesa Majid M. Evaluation of the National cervical cancer screening programme of Bangladesh and formulation of quality assurance guideline FSRH J Fam plannreprod health care 2010; 36(3.)131.

7. Sankaranarayanan. R, Wesley R, Somanathan $T$. et al Visual inspection of the uterine cervix after the application of acetic acid in the detection of cervical carcinoma and its precursors . Cancer. 1998 NOV15; 83(10):21506.

8. BT Utoo PM Utoo SD Ngwan Anzaku SA Daniel MA Cervical intraepithelial neoplasia: Prevalence, risk factors, and utilization of screening services among an urban population in Nigeria ,Tropical journal of obstetrics and gynaecology2016;33(3): 279-283.

9. Poli UR, Bidinger P.D, Gowrishankar S. Visual Inspection with Acetic Acid (VIA) Screening Program: 7 Years Experience in Early Detection of Cervical Cancer and Pre-Cancers in Rural South India.Indian J Community Med. Jul-Sep 2015; 40(3)203-207.

10. Fang -Hui Zhao, Adam $k$ et al Prevalence of human papilloma virus and cervical intraepithelial Neoplasia in china; A pooled analysis of 17 popullation -based study. international journal of cancer 2012 ;131(12);2929-38.

11. WHO guideline for screening and treatment of precancerous lesions for cervical cancer prevention.WHO 2013 library catalogue.

12. Arends $\mathrm{M} \mathrm{J}$, Buckley $\mathrm{C} \mathrm{H}$, Wells M Aeiology, Pathogenesis, and pathology of Cervical Dysplasia J clin pathology 1995 :51(2):96-102.

13. Kietpeerakool C, Kleebkaow P, Srisomboon JHuman Papillomavirus Genotype Distribution among Thai Women with High-Grade Cervical
Intraepithelial Lesions and Invasive Cervical Cancer: a Literature Review.Asian Pac J Cancer Prev. 2015; 16(13):5153-8.

14. Clifford $\mathrm{GM}^{1}$, Rana RK, Franceschi $\mathrm{S}$, Smith JS, Gough G, Pimenta JMHuman papillomavirus genotype distribution in lowgrade cervical lesions: comparison by geographic region and with cervical cancer.Cancer Epidemiol Biomarkers Prev. 2005 May;14(5):1157-64.

15. Monsonego J, Cox JT, Behrens C et al Prevalence of high-risk human papilloma virus genotypes and associated risk of cervical precancerous lesions in a large U.S. screening population: data from the ATHENA trial.GynecolOncol 2015;. Apr; 137(1):47-54.

16. Eduardo L. Franco, Eliane Duarte-Franco, Alex Ferenczy Cervical cancer: epidemiology, prevention and the role of human papillomavirus infectionCMAJ April 03, 2001;164 (7) 10171025

17. Schltech NF, et al Human Papilloma virus infection and risk of progression and regression of cervical intraepithelial neoplasia. J Natl cancer inst sep3 2003; 97(17): 1336

18. Sankaranarayanan R, Budukh AM, RajkumarR.Effective screening programmes for cervical cancer in low- and middle-income developing countries.Bull World Health Organ. 2001;79(10):954-62. ).

19. Saurabh Bobdey, Ganesh BalasubramaniumCancer screening- should cancer screening be essential component of primary health care in developing country? Int J Prev. Med. 2015;656

20. Sanad AS, Kamel HH, Hasan MMPrevalence of cervical intraepithelial neoplasia (CIN) in patients attending Minia Maternity University Hospital.r Arch Gynecol Obstet. 2014 Jun;289(6):1211-7. doi: 10.1007/s00404-0133109-0. Epub 2013 Dec 5.)

21. Ting Kruzikas, Smith JS etal A global review of age-specific and overall prevalence of cervical Iesion Int J Gynecol Cancer Oct.2010; 20(7):1244-9.

22. Partho Basu, Srabani Mittal,Shyam Sundor et al Prevalence of high-risk human papilloma 
virus and cervical intraepithelial neoplasias in a previously unscreened population- A pooled analysis from three studies international journal of cancer Apri, 2013;132 : 1693-1699.

23. Michelle J,Khan,Edward E Patridge, Sophia Wang et al Sociocenomic status and Risk of CIN grade 3among oncogenic HPV DNA( +ve)was with equivocal and mildly abnormal Cytology. Cancer Jul 2005;104(1)61-70.

24. JayaChakravarty, AnkitaChourasia, Minaxi Thakur et al Prevalence of human papillomavirus infection \& cervical abnormalities in HIV-positive women in eastern India .Indian J Med Res. 2016 Jan; 143(1): 79-86.

25. Pretorius, Robert G .Peterson ( 2009) Subsequent Risk and presentation of Cervical Intraepithelial Neoplasia (CIN) 3 or Cancer After a colposcopic Diagnosis of CIN 1 or lessObstetrical and gynecological survey. Mar 62(3) :173-175.

26. S cotton, Sharp, the THOMBOLA group Options for managing Low grade cervical abnormalities detected at screening :cost effectiveness study BJOG $2010 ; 117$ (6) 645 659.

27. Annarosa del Misro, Mario Matteucci, Egle Aba et al Long -term clinical outcome after treatment for High grade lesions, A retrospective Monoinstituional Cohort study Hindawi 2015;03;8

28. WHO guidelines for treatment of cervical intraepithelial neoplasia 2-3 and adenocarcinoma in situ (C) World Health Organization 2014 page 8,9

29. Bishop) A, Sherris J, Tsu VD, Kilbourne-Brook M. Cervical dysplasia treatment: key issues for developing countries.Bull Pan Am Health Organ. 1996 Dec;30(4):378-86.

30. ZF Jesmin, Afroza khanam, Eti Saha et al Clinical effectiveness of VIA and colposcopy based management of CIN Khulna BMA journal $2015: 47(1 \& 2)$ : 16-19

31. Sankaranarayanan R, Thara S, Esmy PO, Basu Cervical cancer: screening and therapeutic perspectives PMed Princ Pract.2008;17(5): 351-64.

32. Baum, Margarete E, Rader, Janet colposcopic Accuracy of Obstetrics and Gynecological Residents - Obstetrical and Gynecological Survey (2007) Mar 62:3:175-176.

33. Ashrafun Nessa, Khadiza Nurun Nahar et al Comparison between Visual inspection of cervix and cytology based screening procedures in Bangladesh Asian pac journal of cancer prevention 2013 ;14:7607-7611.

34. Ashrafun Nessa ,Muhammad Anwar Hussain, Jebun nesa parvin screening for cervical Neoplasia In Bangladesh Using Visual Inspection with acetic Acid - international journal of gynecology and obstetrics 2010 ; 111(2):115-118.

35. Sreedevi A,Javed R, Dinesh A epidemiology of cervical cancer with special focus On India international journals of women Health 2015; 7 : $405-414$. 